\title{
Gasoline Particulate Filter Accelerated Aging Processes - a Literature Review
}

\author{
P. Nagy ${ }^{1 *}$, I. Zsoldos ${ }^{2}$ \\ ${ }^{1}$ Széchenyi István University, Department of Internal Combustion Engines \\ and Propulsion Technology \\ Egyetem tér 1, 9026 Győr, Hungary \\ ${ }^{2}$ Széchenyi István University, Department of Materials Science and \\ Engineering \\ Egyetem tér 1, 9026 Győr, Hungary \\ *E-mail: nagy.peter@ga.sze.hu
}

Abstract: This article briefly presents the testing processes of vehicle and engine testing on chassis and engine dynamometers in a laboratory environment and their development trend due to the stricter environmental regulations. It then explains the test cycles that form the basis of the measurements and their effect on emissions and components of the exhaust system. It briefly summarizes the potential processes of soot formation. It researches and describes the possibilities of reducing the duration and costs of testing and inspection processes in the field of particulate emissions of internal combustion engines

Keywords: particulate filter; engine test bench; test cycle

\section{Types of test bench measurements}

The main purpose of test bench measurements is to measure performance diagnostics and vehicle emissions during vehicle operation. There are two main types, engine test benches and chassis dynamometers. Both types have nearly the same goals, they are mostly under laboratory conditions, but are based on different technology. Their advantage is that the measurements performed under laboratory conditions, so the uniformity and repeatability of the factors influencing the test can be ensured, regardless of the type of vehicle / engine to be measured and human factors. Reproducible and repeatable parameter are the following:

- ambient temperature, 
- engine speed, load changes and operating conditions during the test,

- coolant, oil, intake air and intercooler temperature on engine test bench measurements.

\subsection{Chassis dynamometer}

Over time, several types of chassis dynamometer were used based on different principles. As its name suggests, this measurement is carried out on a finished vehicle (motorcycle, car, truck, etc.), which is the main difference from the engine test bench, where the engine is connected directly to the test equipment.

During the measurements on the chassis dynamometer, the device directly measures the useful power appearing on the wheels of the vehicle, which shows the difference between the power of the engine and the loss of the complete drivetrain. Measurements in both stationary and non-stationary operating conditions can be performed on the chassis dynamometer. The latter makes it possible to carry out the measurement cycles presented in the next chapter, which gives a comprehensive picture of, among other things, the vehicle's fuel consumption, performance and emissions. It is mainly used during technical examinations and post-calibrations.

\subsection{Engine test bench}

Opposite to the chassis dynamometer, the engine test bench measures power and torque values directly on the engine crankshaft. This measurement technology gives us more comprehensive results from the engine. Each of the engine's operating conditions and parameters can be changed to create a test environment that provides accurate results that are close to real operating conditions. It is mainly used for research and development purposes.

\section{Effect of cycles on exhaust after treatment system temperature}

The FTP-75 currently in force, approved by the United States Environmental Protection Agency (US EPA), and the Worldwide Harmonized Light Vehicles Test Procedure (WLTP) developed by the United Nations Economic Commission for Europe (UNECE) are accepted cycles in most countries for measuring fuel consumption and emission values on roller dynamometers [1]. These measurement procedures are used to reproduce the real operating conditions of the vehicles, which also simulate dynamic accelerations, urban as well as highway driving while also taking into account the equipment of the vehicle. As a result of stricter environmental regulations, from September 2017, new type-certified vehicles will also have to comply with EURO 6 regulations on public roads, which will be carried out with the Portable Emissions Measurement System (PEMS) during Real Driving Emission 
(RDE) measurement. In this case, there is no defined cycle, the vehicle is driven in urban traffic, road outside city limits and on the highway. There are test benches, where it is possible to run simulation during RDE measurements [2].

By integrating the chassis dynamometer cycles into the engine test bench, it is possible to measure emissions with more precisely controllable engine operating parameters. Due to the engine test bench environment, more information is available about the operation of the engine, so it gives a better view of the formation of pollutants. For example, how particle emissions change with changes in pre-ignition angle, injection pressure, catalyst and gasoline particulate filter (GPF) temperature. The challenge, however, is that the engine crankshaft is connected to the dynamometer without a transmission, so shifting points must be taken into account when rewriting the cycle.

H. Shao et al. [3] created a three-stage, repeatable measurement cycle, the main features of which are ash filling and thermal aging in the first phase, more dominant thermal aging in the second phase, and soot filling in the third phase. This is a 2.5 hour cycle that is repeated three times. During the stages, the engine operates at constant operating points: first at high speed and medium torque, second at lower speed and high torque, and last at lowest speed and torque. Based on this, the state of the cold start during the repetitions should be ensured, as well as dynamically changing operating points should be included as well.

During the measurements, the engine and the exhaust system heat up with different degrees and at different speeds, which has an effect on the after-treatment of pollutants.

\subsection{Filter temperature change}

A map was made on the change in GPF temperature in the 1000 to $3000 \mathrm{rpm}$ range, where most of the cars are used. The measurement results are shown in Fig. 1. Changes in temperature values are shown as a function of brake effective mean pressure (vertical axis) and speed (horizontal axis). 


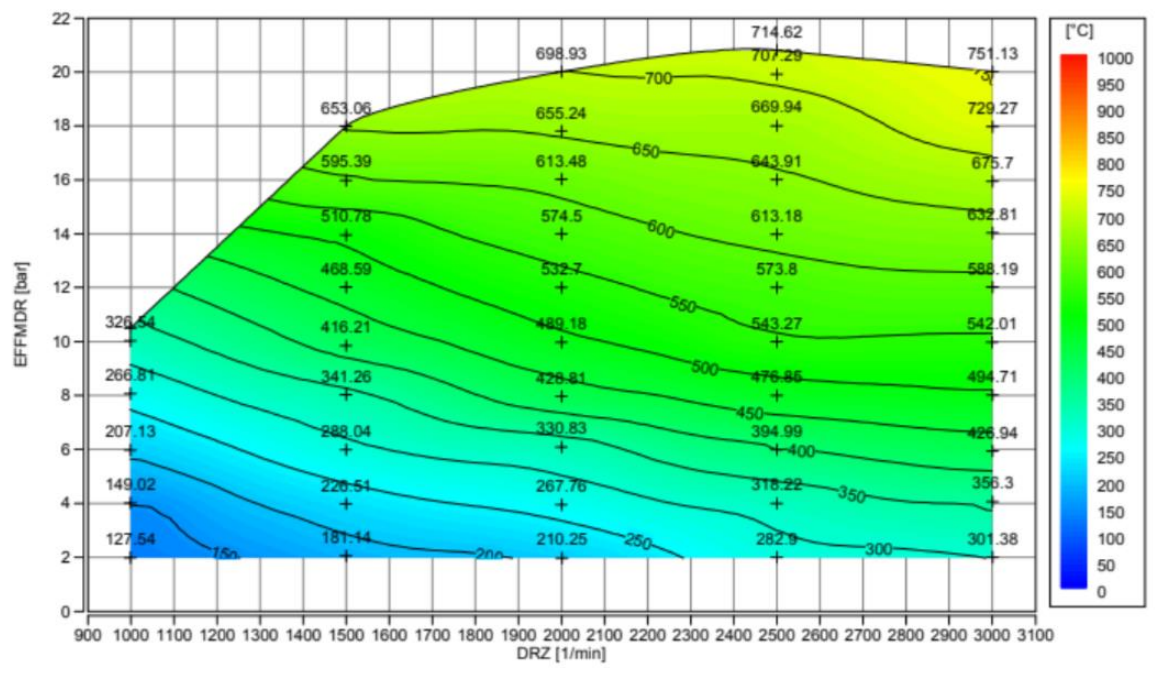

Figure 1. GPF temperature change map

During the measurement, measurement points were in $500 \mathrm{rpm}$ increments and from 2 bar brake mean effective pressure to full load. It was investigated how long it takes to reach a constant temperature in each operating conditions. Based on the measurement, it can be stated that, 4 Minutes of warm-up time is required for stable temperature at each operating point. After 4 minutes, only a small change was observed in some operating conditions, and after 14 bar mean effective pressure, the temperature points were stable after 3 minutes. Achieving a regeneration process at temperatures above about $600^{\circ} \mathrm{C}$, as defined in the literature, requires a speed of at least $1400 \mathrm{rpm}$ at a brake mean effective pressure of $17 \mathrm{bar}$, while at $3000 \mathrm{rpm}$ the soot burns in the filter already at 13 bar, according to Fig. 1 .

In the case of a catalyst, the stable temperature points (due to their local position) have already been reached after 1-2 minutes, these temperature values are shown in Fig. 2. 


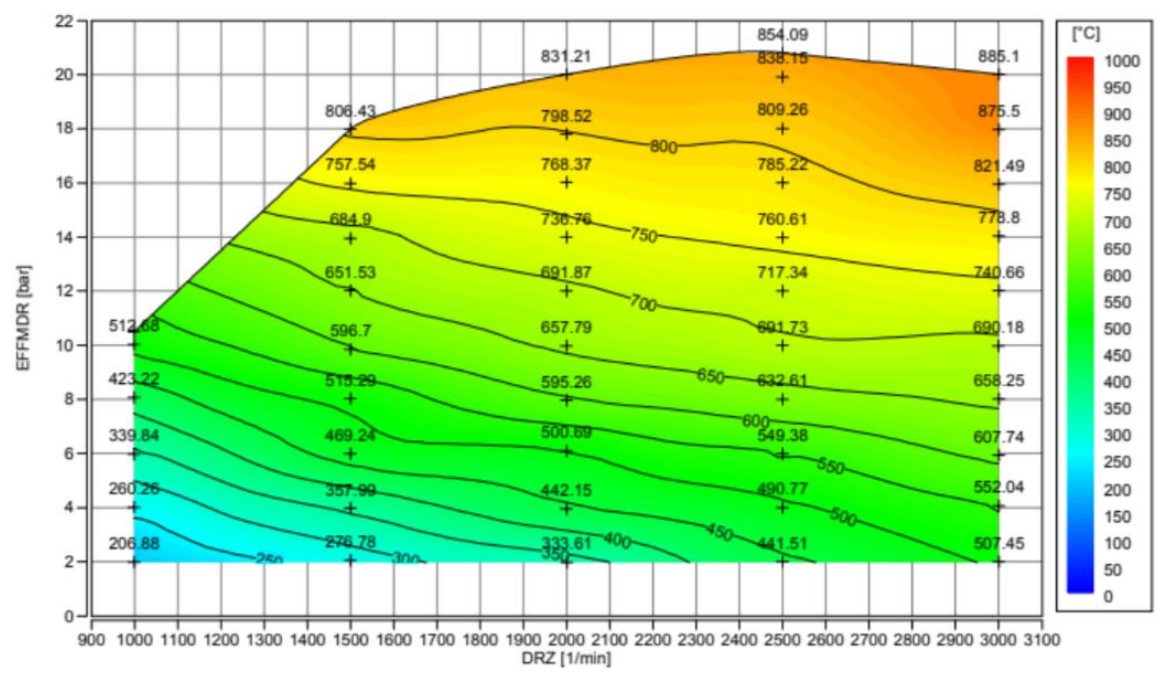

Figure 2. Catalyst temperature change map

If the two curves are matched, it can be stated that at the given measuring points a temperature drop of $\sim 155^{\circ} \mathrm{C}$ can be measured at the distance of the pipe section between the catalyst and the GPF.

It is advisable to reduce the dead times within the cycle and the transition times between the recording of stable temperature values of the operating points, in order to reduce the test bench operating hours and costs. Since the measurements are performed on an engine test bench, the environmental conditions can be reproduced. The duration of the temperature changes during operating point changes can be reduced by an automated cycle. Before the desired operating point measurement, in the first 1-2 minutes after the change (depending on the speed and load), the engine would run at one step higher load and then automatically return to the desired one. During this time, the temperature increases more rapidly, thus reducing the transition time.

\section{Ash in the filter}

Before examining the possibilities of ash build-up acceleration, it is necessary to understand its origins. The test bench measurements described in the previous section require expensive equipment and result in costly measurements. If we want to know the mechanism of the deposition with the help of a particle filter durability test with corresponding on-road vehicle mileage, it will result a huge amount of engine test bench operating hours. Therefore, it is necessary to develop a 
measurement method that will result similar deposits to the real operation with less measurement hours.

\subsection{Reason for using a particulate filter}

It is known that particles smaller than $2.5 \mu \mathrm{m}$ in diameter $\left(\mathrm{PM}_{2.5}\right)$ enter the bloodstream through the human respiratory system, because the respiratory system cannot filter them. Particles play a mediating role, because various toxins adhere to their surface and they carry the toxins with them, so pollutants (e.g. nitrogen oxides, carbon monoxide, hydrocarbons) affect living organisms not only indirectly by environmental pollution, but also directly [4] [5]. Emission standards are showing a gradual strictening trend. Initially, diesel engines were only equipped with a socalled diesel particulate filter (DPF), then the direct injection gasoline engines (GDI) developed for optimized fuel consumption and lower carbon-monoxide emission hat to be equipped with gasoline particulate filter (GPF) in order to reduce the particulate emission and to meet the emission standards [6].

\subsection{Ash forming and deposition}

The ash deposited in the filter is transformed from soot, one of the harmful byproducts of imperfect combustion in the internal combustion engine. Due to the high temperature in the catalyst, a small part of the nano-sized particles is burned and transformed into ash and then trapped in the particulate filter as it travels down the exhaust gas treatment system. Soot and ash particles are trapped in the porous material of the filter.

The particles gradually fill up the filter, and due to the nature of the vehicle operation, the pressure drop value between the two ends of the filter reaches the limit value after a certain period of time. Based on the pressure difference measured before and after the filter, the engine controller detects when the filter build-up reaches the critical value and then it performs a so-called regeneration, which requires an operating condition that causes an elevated exhaust gas temperature, which can be achieved passively or actively. Then the organic part of soot particles will burn, but the inorganic parts will transform into ash, which remain in the filter and result different deposits [7].

It can be observed with different material science tests (CT, EDX etc.), that the components of the ash are mainly magnesium, zinc, phosphorus, calcium, which can found in the lubricating oil and fuel additives, as well as metal wear particles from various engine components [8]. The following processes, for example, also affect the quality of combustion, as well as the formation of particles:

- fuel injection pressure, 
- exhaust gas recirculation (EGR),

- cold start, engine and intake air temperature,

- oil consumption,

- crankcase gas recirculation,

○ blow-by,

○ oil evaporation (30-40\% of the whole oil consumption),

○ oil consumption (valve guides, piston rings) [9].

In terms of accelerated, artificial aging of the GPF, the effect of cold start, oil consumption and the possible utilization of them for artificial aging will be described in detail in the following.

\subsection{Effect of cold start on particulate emission}

According to the studies of T. Chan et al. [10] and A. Joshi et al. [11], cold start produces the largest number of particulate emissions. During a cold start, the change in the ambient air temperature has a high influence [12] [13]. E. Nam et al. [14] has shown that with every $20^{\circ} \mathrm{F}$ ambient temperature drop, PM emissions are doubled, which is tracked back to the enriched mixture. According to the studies of M. S. Reiter and K. M. Kockelman, nearly $97 \%$ of cold-start particulate emissions are $50 \mathrm{~nm}$ in diameter particles, which are particularly harmful to health [15].

Under real conditions, cold start is affected by several factors, such as: the engine temperature reached during operation, the time elapsed between shutdown and restart, the ambient temperature, and the thermal insulation of the exhaust gas after treatment system. According to a survey done in 2016 by the European Federation for Transport and Environment, 40\% of the trips end with $4 \mathrm{~km}$ in an urban environment (where air quality is worse) and $27 \%$ of starts are cold starts [16].

\section{Acceleration of ash deposition}

Based on the previous chapters, different ash deposition acceleration procedures were examined. It can basically be done by modifying engine operating parameters or by developing and implementing an additional device.

The aim for accelerating the ash deposition:

- backpressure examination,

- investigation of changes in filtration efficiency, 
- measuring pressure drop,

- reducing filter run-in time.

\subsection{Accelerated aging systems}

Several researchers have worked on a so-called artificial aging process, which can speed up the deposition and mechanisms in the particle filter. Youngquist et al. [17] chose the most obvious way to achieve this goal. A relatively high-displacement (517 cc) single-cylinder diesel engine was selected with low-budget and maintenance costs, which exhaust gas after treatment system was equipped with an additional fuel pump, air supply and temperature management system before the filter. This way extra soot formation was possible. The principle of most concepts is as follows: air and fuel are fed into a combustion chamber and then burned, the combustion product is fed to the filter through a branch while the engine is running on the test bench or as a separate unit the filter is connected on the aging device directly.

Sappok et al. [9] designed a separate device whose main components were: diesel burner, combustion chamber, lubricant oil injector, and a heat exchanger that allows precise control of the temperature of the produced gas. Compared to the previous concept, more particulate mass (PM) could be generated by burning lubricating oil and had a similar composition, diameter and geometry compared to those from internal combustion engines.

The previous solutions were for DPF aging, which was further developed by James E. Jorgensen to be suitable for GPF as well. Opposite to diesel, gasoline has a high evaporation property, volatile and is easily oxidized, as a result of these a selfsustaining flame and continuous combustion cannot be ensured in a conventional oil burner. As a result, it was necessary to redesign the combustion chamber, with continuous spark ignition. A swirling blade was also designed to provide the right mix of fuel and air for idealized combustion [18]. A schematic diagram of the concept is shown in Fig. 3. 


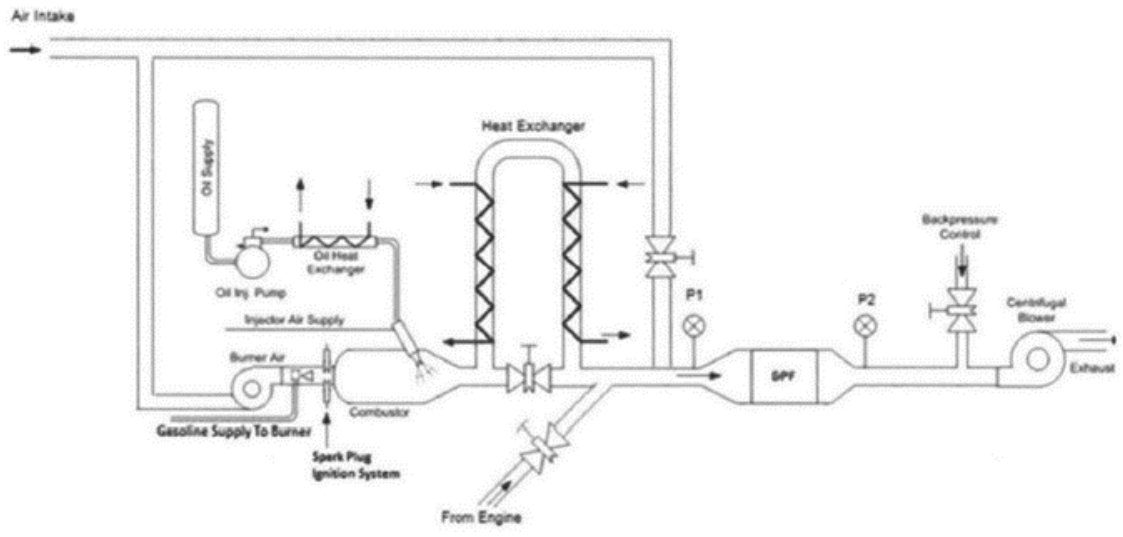

Figure 3. GPF aging system [18]

A number of temperature sensors were installed in the system to provide the data needed for precise control. By installing valves, the operation in parallel with and without the internal combustion engine was also possible. Sterlepper1et al. [19] studied the optimal design and operation of the oil injector for this concept with different secondary air temperatures and mass flows at different nozzle sizes.

The advantage is that the air-fuel ratio as well as the amount of oil to be injected can be controlled quickly and precisely, the reaction time of the control system is shorter than that of an internal combustion engine. The operating point of the device can be freely modified according to the desired measurement, the particle emissions of the cold start or the stoichiometric operation can be reproduced.

The length of the test cycles associated with the aging equipment is usually given in $\mathrm{km}$, it depends on which type of test I choose (NEDC, WLTP, FTP-75 etc.). The goal is to accelerate the optimal value of the filtration efficiency of the filters. This depends to a large extent on the parameters influencing the combustion, the amount and composition of the oil burned.

\subsection{Cold start cycle}

After performing the relevant cycles presented earlier, based on current experience, in order to start the measurement again from a cold start state (the temperature of the engine and exhaust gas after treatment units falls back to the initial value), a waiting time of almost one hour from the warm state is required without external intervention. Reducing the engine temperature is possible at a fast rate with the ventilation system, while the temperatures required for valid measurements (TWC, GPF) are decreasing at a slow rate. To speed this up, when 
creating the test cycle relatively fast cooling can be achieved until the exhaust temperature is reached by the components by running the engine at lower load and medium speed. Thereafter, for cooling to ambient temperature, if it is possible to prepare the exhaust system, a high degree of cooling can be achieved after the engine has been shut down by installing an exhaust system ventilation device before the catalytic converter.

\subsection{Blow-by}

Several studies have been performed to understand the effect of blow-by on particle number. With the help of a custom-made crankcase gas precipitator, in which the crankcase gas is collected and then precipitated, the chemical analysis of the resulting liquid is possible. The main ash-forming elements are coming from the additives of engine oils, which are mainly magnesium, zinc, phosphorus, calcium [20]. As the crankcase gas is recirculated into the intake manifold due to the engine's design, it is advisable to look for changes in the precipitated material compared to the engine oil and to apply the results to the formation of soot particles. Cold start also has an effect on blow-by formation, so increasing its frequency is also important for the blow-by [21]. By eliminating the crankcase gas filter, the unfiltered crankcase gas enters the combustion chamber when it is recirculated into the intake manifold, which increases the particulate emissions and thus aids the aging process.

\subsection{Additional options}

In addition to eliminating the crankcase gas filter, higher engine breakdown can also increase oil consumption. S. Eakle et al. [22] came up with a solution that, by installing the oil scraper ring upside down, would allow excess oil to enter the combustion chamber, thereby increasing particulate emissions. By increasing the particulate emissions with upside down oil scraper ring, other negative effects on the engine and combustion must be taken into account as well.

Prior to saturation tests on the filters, the filters shall be heated up to ensure no water vapor is present in the filter body during the precision measurement, also soot shall be burned out for examining the remaining ash. For this, an ECTO-Lab burner was used. In addition, the exhaust gas was lead through a heat exchanger for precise temperature control [22].

\section{Measurement process}

The aim was to design a test cycle where the main focus is on examining the particle emissions, with proper control in each operating point. 
Before aging the GPF, its weight has to be measured while heated up, so later, after the defined test bench operating hours and re-measuring the weight, the ash deposit can be calculated [18]. The main aspects of the measurement cycle design are the following:

- It must be possible to quickly reach the desired temperature (high or low) in the filter, even by designing and implementing auxiliary equipment.

- Include only small dead-times (warm-up and cool-down times) during cycles

- Possibility of repeated cold start particulate emission measurement

- Be automatic (start, perform measurements at stable operating points, stop, cool, then repeat the process)

The aging equipment to be installed during the run of the cycle is also integrated into the measurement process, which can be used to control and speed up the filter ash build-up.

The operation and test results with the new device will be presented later.

\section{References}

[1] J. Jang, J. Lee, Y. Choi, S. Park, Reduction of particle emissions from gasoline vehicles with direct fuel injection systems using a gasoline particulate filter, Science of The Total Environment 644 (2018) pp. 14181428 .

doi: https://doi.org/10.1016/j.scitotenv.2018.06.362

[2] H. Zellbeck, R. Walter, M. Stiegler, RDE - Real Driving at the High Dynamic Engine Test Bench. MTZ Worldwide 76 (2015) pp. 22-27. doi: https://doi.org/10.1007/s38313-014-1007-x

[3] H. Shao, G. Carpentier, D. Yin, Y. Wang et al., Engine Accelerated Aging Method Developed to Study the Effect of Lubricant Formulations on Catalyzed Gasoline Particulate Filter Durability, SAE Technical Paper (2018) doi: https://doi.org/10.4271/2018-01-1804

[4] C. Wang, Y. Tu, Z. Yu, R. Lu., $\mathrm{PM}_{2.5}$ and Cardiovascular Diseases in the Elderly: An Overview. International Journal of Environmental Research and Public Health 12 (7) (2015) pp. 8187-8197. doi: https://doi.org/10.3390/ijerph120708187 
[5] WHO, Ambient (outdoor) air pollution (2018) [cited 2020-04-28].

URL http://www. who. int/news-room/factsheets/detail/ambient-(outdoor)-air-quality-and-health

[6] C. McCaffery, H. Zhu, C. Li, T. D. Durbin, K. C. Johnson, H. Jung, G. Karavalakis, On-road gaseous and particulate emissions from GDI vehicles with and without gasoline particulate filters (GPFs) using portable emissions measurement systems (PEMS). Science of The Total Environment 136366 (2019)

doi: https://doi.org/10.1016/j.scitotenv.2019.136366

[7] A. Sappok, Y. Wang, R. Wang, C. Kamp, V. Wong, Theoretical and Experimental Analysis of Ash Accumulation and Mobility in Ceramic Exhaust Particulate Filters and Potential for Improved Ash Management, SAE International Journal of Fuels and Lubricants 7 (2) (2014) doi: https://doi.org/10.4271/2014-01-1517

[8] A. Liati A. Spiteri, P. Dimopoulos Eggenschwiler, N. Vogel-Schäuble, Microscopic investigation of soot and ash particulate matter derived from biofuel and diesel: implications for the reactivity of soot, Journal of Nanoparticle Research 14 (2012) 1224. doi: https://doi.org/10.1007/s11051-012-1224-7

[9] A. G. Sappok, D. Beauboeuf, V. W. Wong, A Novel Accelerated Aging System to Study Lubricant Additive Effects on Diesel Aftertreatment System Degradation, SAE International Journal of Fuels and Lubricants 1 (1) (2009) pp. 813-827.

doi: https://doi.org/10.4271/2008-01-1549

[10] T. Chan, E. Meloche, J. Kubsh, R. Brezny, Impact of Ambient Temperature on Gaseous and Particle Emissions from a Direct Injection Gasoline Vehicle and its Implications on Particle Filtration. SAE International Journal of Fuels and Lubricants 6 (2) (2013) pp. 350-371.

doi: https://doi.org/10.4271/2013-01-0527

[11] A. Joshi, T. Johnson, Gasoline Particulate Filters - a Review. Emission Control Science and Technology 4 (2018) pp. 219-239.

doi: https://doi.org/10.1007/s40825-018-0101-y 
[12] H. Badshah, D. Kittelson, W. Northrop, Particle Emissions from Light-Duty Vehicles during Cold-Cold Start, SAE International Journal of Engines 9 (3) (2016) pp. 1775-1785.

doi: https://doi.org/10.4271/2016-01-0997

[13] A. S. Ramadhas, H. Xu, Cold start particle number, size and mass emissions from a CRDI diesel engine running on biodiesel blends in a cold environment, Biofuels 7 (4) (2016) pp. 353-363.

doi: https://doi.org/10.1080/17597269.2015.1138037

[14] E. Nam, S. Kishan, R. W. Baldauf, C. R. Fulper, M. Sabisch, J. Warila, Temperature Effects on Particulate Matter Emissions from Light-Duty, Gasoline-Powered Motor Vehicles. Environmental Science \& Technology 44 (12) (2010) pp. 4672-4677.

doi: https://doi.org/10.1021/es100219q

[15] M. S.Reiter, K. M.Kockelman. The problem of cold starts: A closer look at mobile source emissions levels. Transportation Research Part D: Transport and Environment 43 (2016) pp. 123-132.

doi: https://doi.org/10.1016/j.trd.2015.12.012

[16] M. Weiss, E. Paffumi, M. Clairotte, Y. Drossinos, T. Vlachos, P. Bonnel, B. Giechaskiel. Including cold-start emissions in the Real-Driving Emissions (RDE) test procedure (2017)

doi: https://doi.org/10.2760/70237

[17] A. Youngquist, K. Nguyen, B. Bunting, T. Toops, Development of an Accelerated Ash Loading Protocol for Diesel Particulate Filters, SAE Technical Paper (2008) 2496.

doi: https://doi.org/10.4271/2008-01-2496

[18] J. E. Jorgensen, Developing an Accelerated Aging System for Gasoline Particulate Filters and an Evaluation Test for Effects on Engine Performance, Massachusetts Institute of Technology, Department of Mechanical Engineering (2010) [cited 2020-04-28].

URL http://hdl. handle.net/1721.1/92137

[19] S. Sterlepper, J. Claßen, S. Pischinger, Design of a Novel Gasoline Particulate Filter Aging Method, Emission Control Science and Technology (2019) doi: https://doi.org/10.1007/s40825-019-00130-5 
[20] C. Lambert, M. Bumbaroska, D. Dobson, J. Hangas, J. Pakko, P. Tennison, Analysis of High Mileage Gasoline Exhaust Particle Filters, SAE International Journal of Engines 9 (2) (2016)

doi: https://doi.org/10.4271/2016-01-0941

[21] B. J. Mitchell, A. Zare, T. A. Bodisco, M. N. Nabi, F. M. Hossain, Z. D. Ristovski, R. J. Brown, Engine blow-by with oxygenated fuels: A comparative study into cold and hot start operation. Energy 140 (2017) pp. 612-624.

doi: https://doi.org/10.1016/j.energy.2017.08.115

[22] S. Eakle, S. Avery, P. Weber, C. Henry, Comparison of Accelerated Ash Loading Methods for Gasoline Particulate Filters, SAE Technical Paper, (2018)

doi: https://doi.org/10.4271/2018-01-1703 